\title{
União Internacional Protetora dos Animais de São Paulo: práticas, discursos e representações de uma entidade nas primeiras décadas do século XX
}

\author{
International Union for the Protection of Animals \\ of São Paulo: practices, discourses and representations \\ of an organization in the first decades of the $20^{\text {th }}$ century
}

Natascha Stefania Carvalho de Ostos ${ }^{\star 1}$

\section{Resumo}

O artigo examina a trajetória da União Internacional Protetora dos Animais de São Paulo nas primeiras décadas do século $\mathrm{XX}$. Com base em jornais diários publicados no estado e na revista Zoophilo Paulis$t a$, editada pela entidade, analisamos suas ações e estratégias discursivas no intuito de sensibilizar a população e o poder público para a necessidade de proteger os animais. No meio urbano em expansão a convivência entre humanos e animais se apresentava como um desafio, exigindo mudanças e adaptações na forma de lidar com os bichos, o que envolvia aspectos sociais, políticos, econômicos e culturais. Nesses termos, pensar os animais foi um importante exercício de reflexão para se questionar a violência humana e os limites da exploração econômica e da ação do homem sobre a natureza.

Palavras-chave: animais; associação protetora; imprensa.

\section{Abstract}

The article examines the trajectory of the International Union for the Protection of Animals of São Paulo in the first decades of the 20th century. Based on daily newspapers published in the state and the magazine Zoophilo Paulista, edited by the organization, we analyze their actions and discursive strategies in order to sensitize the citizens and the government to the need of protect animals. In an expanding urban environment, human-animal coexistence was a challenge, requiring changes and adaptations in the way of dealing with animals, which involved social, political, economic and cultural aspects. In these terms, thinking about animals was important to question human violence, the limits of economic exploitation and of human action on nature.

Keywords: animals; protection society; press.

\footnotetext{
* Departamento de História, Universidade Federal de Minas Gerais (UFMG). Belo Horizonte, MG, Brasil. nataschaostos@hotmail.com
} 
"Eu tenho uma proposta para te fazer / Eu, você, dois filhos e um cachorro”. O refrão integra a letra da música Cê Topa, do cantor Luan Santana, lançada no ano de 2013. ${ }^{2}$ Sucesso estrondoso à época, o estribilho aponta para o fato de que, na visão de muitos brasileiros de hoje, o núcleo familiar não se restringe mais aos humanos. A "proposta" da música tem como base do ideal de felicidade alguns pressupostos: o amor romântico conjugal, o desejo por filhos (apenas dois, seguindo a tendência da maioria das famílias de classe média da zona urbana), e introduz um novo elemento, o cachorro. $O$ cão, no singular, reforça a natureza individualista do projeto, o animal é acolhido como membro de um pequeno agrupamento privado, voltado para si, em que cada qual tem um papel na troca de afetos que mantém a estabilidade interna da unidade domiciliar desejada.

Animais sempre estiveram presentes nos lares do país, contudo, com base em uma quantidade sólida de dados, é possível afirmar que o Brasil vive um momento de inflexão na percepção e na sensibilidade relativas aos bichos de estimação. O Instituto Brasileiro de Geografia e Estatística (IBGE) divulgou, em junho de 2015, Pesquisa Nacional de Saúde (PNS) com informações colhidas no ano de 2013. O resultado evidencia a grande importância dos animais na vida cotidiana dos brasileiros. "Em 2013, 44,3\% dos domicílios do país possuíam pelo menos um cachorro ... A população de cachorros em domicílios brasileiros foi estimada em 52,2 milhões ... Em relação à presença de gatos, $17,7 \%$ dos domicílios possuíam pelo menos um”. A imprensa deu destaque à pesquisa, ressaltando que o resultado revelava existirem mais cachorros do que crianças nos domicílios brasileiros, já que o número de crianças somava 44,9 milhões. ${ }^{3}$ Essa realidade vem acompanhada do crescimento impressionante dos negócios voltados para tal segmento. A Associação Brasileira da Indústria de Produtos para Animais de Estimação (Abinpet), em balanço divulgado sobre o ano de 2015, informou que o setor lucrou nada menos do que 18 bilhões de reais, registrando crescimento de 7,6\% em relação a $2014 .{ }^{4}$

A história, sempre atenta aos anseios e às demandas do tempo presente, não pode ficar alheia a esse fenômeno. É na área de História Ambiental que encontramos estudos sistemáticos sobre o tema, mas tais estudos ainda são incipientes no Brasil diante da vastidão do campo a explorar e das pesquisas já realizadas em outros países, notadamente nos Estados Unidos, na Inglaterra e na França. ${ }^{5}$ Os historiadores brasileiros são responsáveis por uma importante produção voltada para a problematização das relações construídas entre o homem e a natureza, seus trabalhos possuem inegável qualidade e alcance 
internacional, contudo, no que toca ao âmbito do estudo sobre os animais as investigações são escassas (Duarte, 2002; 2006; Aprobato, 2007; Sanjad et al., 2012; Vieira, 2015). Notadamente a partir do século XXI os estudos voltados para as áreas florestais e campestres passaram a coexistir com investigações interessadas em examinar as correlações entre a natureza e o meio urbano no Brasil, tendo em vista a alta concentração de habitantes nessas áreas, e como as cidades se organizaram historicamente em termos de arborização, canalização de rios, enchentes e secas, combate a vetores de doenças, produção do lixo e, obviamente, o trato dos animais ali presentes (Duarte; Ostos, 2005; Duarte, 2007; Sedrez, 2007). Nesse sentido, logo se constata que para além da importância dos bichos para a humanidade, como alimento, força de trabalho e fonte de materiais, eles também têm "sido foco da atenção humana em instâncias que alteraram as percepções humanas - em filmes, zoológicos e fotografias, por exemplo, e na ciência, ou como animais de estimação, e no esporte" (Fudge, 2013, p.IX, trad. NO).

Este artigo se insere no esforço de pensar os animais como parte fundamental da história, compreendendo que a própria ideia do que significa ser um humano necessita dos animais para ser construída, e que tal operação tem levado o homem a refletir sobre questões como: quem pode ser titular de direitos, os limites da ação dos homens sobre as outras espécies, quais os fundamentos biológicos e filosóficos que embasam a diferenciação e a hierarquia entre os bichos etc. (Galvão, 2010). Nosso enfoque não recai sobre os animais em si, ${ }^{6}$ e sim nos aspectos culturais, sociais e políticos envolvidos na construção de práticas e discursos sobre os bichos e na interação homem-animal, levando em conta, principalmente, que "Muitas das pesquisas atuais no campo de estudo homem-animal estão politicamente ligadas com o movimento em defesa dos direitos dos animais" (Tortorici; Few, 2013, p.9, trad. NO). Nesse viés existem trabalhos acadêmicos que se preocuparam em traçar a história das entidades protetoras, notadamente nos Estados Unidos (Favre; Tsang, 1993) e na Europa (Agulhon, 1981; Amaro; Felgueiras; Lencastre, 2013) com alguma produção na América do Sul (Monzote, 2013). No caso do Brasil encontramos menções às sociedades defensoras dos bichos como parte de pesquisas mais amplas, mas não como objeto central (Aprobato, 2007).

Nossa proposta é examinar a atuação da União Internacional Protetora dos Animais de São Paulo, mediante análise de notícias de jornais diários e da revista publicada pela entidade. Tal impresso constitui fonte privilegiada para o estudo de "como dada sociedade pensa os animais, constrói um estatuto 
para eles, inventa, abandona, transforma seus usos segundo a vontade de intervenção de grupos portadores de sensibilidades e de necessidades diferentes" (Baratay; Mayaud, 1997, p.433, trad. NO).

\section{A revista Zoophilo Paulista}

A União Internacional Protetora dos Animais (UIPA) foi a primeira sociedade do tipo criada no Brasil, na cidade de São Paulo, no ano de 1895, e ainda em atividade nos dias de hoje. ${ }^{7}$ Fundada por figuras destacadas da elite paulista (políticos, juristas, escritores e professores), a associação teve como um dos seus iniciadores Ignácio Wallace da Gama Cochrane (1836-1912), engenheiro e deputado paulista engajado em vários projetos, como na organização, em 1903, do Instituto Pasteur de São Paulo, referência no combate à raiva e na pesquisa de vacinas e produtos veterinários (Teixeira; Sandoval; Takaoka, 2004). Tendo nascido da iniciativa de pessoas abastadas, social e politicamente influentes, não tardou que a entidade ganhasse robustez patrimonial e trânsito entre as autoridades públicas e a imprensa. Com sede própria na Vila Mariana, hoje parque do Ibirapuera, e reunindo cerca de 2.500 sócios no ano de 1930, as ações do grupo se expandiram rapidamente, e já na década de 1920 contava com um cemitério para animais e, no ano de 1929, um hospital dedicado a socorrer os bichos da cidade, promovendo atendimento gratuito aos animais cujos donos não possuíam condição financeira para arcar com os custos dos tratamentos. ${ }^{8}$

A associação lançou em maio de 1919 a revista Zoophilo Paulista, editada mensalmente e distribuída principalmente no estado de São Paulo, tendo como editor chefe João Caiaffa, professor e tradutor. Trata-se de periódico raro nos arquivos, razão pela qual não conseguimos demarcar com precisão em qual data teria findado, porém encontramos referências à publicação em jornais diários de São Paulo até o ano de 1932. A criação do impresso e sua edição por tantos anos atestam a saúde financeira da entidade, capaz de canalizar recursos para além da sua atividade fim e ainda assim manter uma ampla estrutura imobiliária e de prestação de serviços. A proposta de lançar um periódico inteiramente dedicado ao tema da proteção aos animais e à divulgação da causa era uma proposta editorial inédita no Brasil. É provável que o projeto tenha se inspirado em revista congênere portuguesa, criada em 1876 pela Sociedade Protetora dos Animais do país, e intitulada Zoophilo (Amaro; Felgueiras; Lencastre, 2013, p.17). O título da publicação brasileira demarca e circunscreve 
o campo de ação da entidade, o estado de São Paulo, colocando em relevo o pioneirismo dos paulistas na defesa dos animais. Traçava-se, assim, a origem geográfica do movimento, informando o leitor de que o conteúdo versaria, predominantemente, sobre temas e acontecimentos ligados à realidade local.

Medindo 18 x 27 centímetros, o periódico era todo editado em papel couché, evidenciando que a entidade tinha fundos para investir em um detalhe que encarecia o custo da publicação. Predominava o preto e branco, exceto em algumas capas, que estampavam uma figura monocromática, e internamente a publicação trazia muitas fotos. Com média de 25 páginas, os exemplares a que tivemos acesso não possuíam indicação de preço avulso, mas por volta de 1930 a assinatura anual custava $10 \$ 000$. A revista continha propagandas anunciando alimentos, medicamentos, vestuário e máquinas, além da oferta de serviços variados. A maioria dos anúncios apregoava produtos de consumo humano, revelando que o mercado de bens voltados para animais era incipiente, e que a demanda, mesmo para os animais de estimação, era quase somente por alimentos e remédios, necessidade suprida por estabelecimentos especializados na vida agrícola, como a Casa Orestes, que vendia desde galinhas, canários e cachorros até "sementes de hortaliças, específicos veterinários, etc.". As propagandas, o sistema de assinaturas e os próprios recursos da entidade garantiram a edição da revista por pelo menos 13 anos, feito digno de nota considerando tratar-se de entidade filantrópica e o fato de a revista cobrir um nicho editorial muito especializado, distribuída no estado de São Paulo.

Zoophilo Paulista trazia informações importantes sobre o projeto e as ações da UIPA. Seu intuito era educar os leitores e divulgar as ações do grupo, que incluíam: socorro aos animais abandonados e feridos nas ruas, verificação de denúncias de crueldade, propostas de implantação e melhoria de serviços públicos envolvendo os animais, oferecimento de abrigo e cuidados veterinários a animais necessitados etc. A revista dedicava-se prioritariamente ao universo adulto, mas também contava com algum conteúdo dirigido às crianças. O tom geral do periódico era de caráter informativo e noticioso, tratando de assuntos bastante específicos, como as condições do comércio dos animais, os procedimentos adotados nos abatedouros, iniciativas governamentais, artigos debatendo os direitos dos animais, fotos de bichos feridos ou maltratados etc. O impresso não tinha seções fixas, os temas se sucediam sem ordem aparente, tratando de curiosidades sobre o mundo animal, episódios de "heroísmo" de animais, debate sobre códigos de postura e legislação, fotografias e relatos de pessoas envolvidas na causa, imagens de animais com seus donos, tradução de 
textos estrangeiros sobre a temática, casos de crueldade, abandono e acidentes etc. Mesclavam-se na publicação narrativas exaltando a ternura na relação homem-animal - como poemas, relatos edificantes sobre a fidelidade dos animais, fotografias enviadas por leitores com seus bichinhos - com notícias e imagens brutais, expondo episódios de crueldade e de descaso.

A rubrica era ampla, mas predominava nitidamente o interesse pelo destino dos animais domésticos, ${ }^{10} \mathrm{em}$ especial aqueles presentes no meio urbano. Nas primeiras décadas do século XX as principais cidades do país passaram por profundas transformações urbanísticas, de uso e ocupação do espaço. $\mathrm{O}$ grande afluxo de imigrantes, a crescente industrialização e a renda oriunda do café garantiram à capital paulista um crescimento impressionante na década de 1920 (Arias Neto, 2006, p.226-227). A demanda populacional e os recursos econômicos impulsionaram a expansão de serviços tais como iluminação pública, bondes elétricos, abertura de vias e número crescente de automóveis. A transição de um ambiente pacato para uma cidade movimentada não se deu sem descompassos, pois nesse contexto os animais ainda permaneciam como agentes importantes para o funcionamento da cidade e para o desempenho de trabalhos, puxando bondes e carroças, como meio de transporte, energia motriz e suportando pesos. Ao mesmo tempo as vias amplas e pavimentadas recebiam os trilhos de bondes e carros, cuja velocidade era muitas vezes incompatível com a destreza de animais sobrecarregados e assustados.

Zoophilo Paulista enfatizava continuamente as mortes de animais por atropelamento, denunciando a velocidade excessiva, a imprudência dos condutores e, após o sinistro, o abandono dos bichos na via pública sem qualquer socorro. Para causar maior impacto no leitor essas notícias eram ilustradas com fotografias das cenas dos acidentes, expondo cavalos, burros, bois e cães mortos ou feridos, focalizando sangue e até vísceras expostas. A brutalidade da máquina contrastava com a fragilidade e a impotência dos animais, submetidos, pela incúria humana, a todo tipo de situação perigosa. A UIPA contava com uma linha telefônica, que mantinha até mesmo um plantão noturno, por meio da qual os cidadãos poderiam acionar a entidade, que então enviava equipe de socorro, resultando quase sempre no sacrifício do bicho, dada a gravidade dos ferimentos; "vemos o animal da boleia sacrificado pelo Veterinário da União Internacional Protetora dos Animais, por estar o muar com a barriga toda rasgada, pondo à vista o estômago muito perfurado, como mostra a fotografia. Ocasionou este desastre um auto-ônibus". ${ }^{11}$ Mas o campo de atuação do grupo era amplo e seu trabalho estava longe de limitar-se a casos 
particulares, a proposta era estabelecer mudanças gerais no modo de os brasileiros lidarem com os bichos.

\section{União Internacional Protetora dos Animais: DISPUTAS, RELAÇÕES COM A IMPRENSA E O PODER PÚBLICO}

Em que pese o prestígio da UIPA em razão de sua longa história e dos serviços prestados aos animais, a entidade não gozava de aprovação unânime nos meios de comunicação, nem entre os próprios defensores dos animais. Não raro jornais diários reproduziam reclamações de leitores descontentes com a falta de amparo da associação e com a demora no atendimento. Essa insatisfação se manifestou no seio do próprio grupo, pois em março de 1932 um ramo dissidente da UIPA abandonou os seus quadros e fundou a Sociedade Paulista Protetora dos Animais. O fato foi noticiado na imprensa e as justificativas indicavam discordância na administração dos recursos, no atendimento e na equanimidade dos sócios na tomada de decisões, culminando na perda das eleições internas pela chapa dissidente. A nova entidade inicialmente pautou a sua identidade em contraposição ao que definia como atuação negativa da União Internacional, "agremiação que jamais cuidou dos verdadeiros fins zoophilos visados em seus estatutos ... Pouca gente sabia onde era a sua sede. $\mathrm{Na}$ lista telefônica não aparecia o número do aparelho da associação. Parecia, até, uma instituição clandestina". ${ }^{12}$ Criticava-se a suposta apatia do agrupamento e a sua pressa em sacrificar animais acidentados sem antes esgotar todos os recursos de tratamento, principalmente no caso dos bichos de grande porte, de transporte difícil. "Chegando, os representantes da Protetora julgaram de bom alvitre matar a besta. Impediu-os de fazê-lo o veterinário que também já ali se achava, dizendo-lhes que primeiro era preciso ver se não se podia encontrar remédio para atalhar o mal ... hoje, o animal, em perfeita saúde, continua a trabalhar...". ${ }^{13}$ Condenava-se também a inacessibilidade dos serviços para animais cujos proprietários não tinham boa condição econômica: "Parece que mantém um hospital para cães de luxo e uma necrópole com terrenos que custam os olhos da cara - tão caros como os da Consolação”. Acusavam o grupo de descaso e tibieza em suas ações educativas e de divulgação, apontando até mesmo deslizes de comunicação, mas com carga simbólica, para atacar a entidade, tendo um repórter descoberto uma placa da sociedade na avenida São João, com os dizeres "Não maltrate os Animais - S.U.I. Protetora dos 
Animais", afixada na fachada de um açougue... Dizia o artigo: "Fora, o 'não maltrate os animais' ... Dentro, deixando-se mostrar, através das grades das portas, os quartos cheios de sangue e as costelas de um boi paciente que morreu... para nós". ${ }^{14}$

Além de essas controvérsias serem reveladoras de discordâncias quanto à administração e aos fins de uma associação protetora, tais disputas atestam a força da causa animal naquele momento, capaz de mobilizar uma quantidade razoável de cidadãos envolvidos com o ativismo organizado, concorrendo no espaço da mesma cidade por apoio da imprensa, reconhecimento das autoridades e simpatia (e doações) da população. Apesar das censuras a União Internacional Protetora dos Animais gozava de prestígio junto à imprensa em geral e o governo. Seus dirigentes eram pessoas bem relacionadas da elite paulista, como René Thiollier, advogado e escritor, membro da Academia Paulista de Letras, sócio do Instituto Histórico e Geográfico de São Paulo e da Associação Paulista de Imprensa, envolvido com a Semana de Arte Moderna de 1922, engajado no movimento Constitucionalista de 1932, tendo assumido a presidência da entidade em 1927 (Pinheiro, 2014, p.46).

A UIPA se destacava pelas constantes tentativas de diálogo com o poder público em todas as esferas governamentais, instando as autoridades a criar leis e regulamentos a favor dos animais, pedindo ação policial e aplicação das normas existentes. Desde o fim do século XIX o grupo mantinha parceria oficial com a prefeitura de São Paulo, como auxiliar na execução de regulamentos oficiais destinados a recolher animais abandonados nas ruas e a sacrificá-los: "mesmo sendo abolidas as bolas envenenadas, o principal elemento no controle da população canina da cidade continuou a ser o sacrifício sumário e, por mais paradoxal que possa parecer, a entidade incumbida oficialmente de tal prática, foi a Sociedade Internacional Protetora dos Animais" (Aprobato, 2007, p.139). Até por volta de 1909 o município designava dotações financeiras para que a associação cuidasse do depósito de animais, mas o número de bichos que circulavam pela cidade excedia a capacidade de ação do grupo, resultando em insatisfações tanto do poder público como da população (Aprobato, 2007, p.143, p.147). Tal fenômeno não foi exclusivo da cidade de São Paulo, pois grandes centros urbanos, como Nova York, enfrentavam o mesmo problema e também recorreram ao auxílio das associações civis na tentativa de controlar o fluxo e a presença de animais. De acordo com Jessica Wang tal cenário desafia pressupostos estabelecidos sobre grupos protetores, evidenciando que ao longo da história eles não se restringiram a atuar como 
educadores e divulgadores da causa, tendo desempenhado papel público relevante ao assumirem poderes de fiscalização e de polícia, "exercendo autoridade estatal juntamente com agências governamentais formalmente constituídas, por vezes em um espírito de cooperação, outras vezes com intensa rivalidade" (Wang, 2012, p.999, trad. NO).

Assim é que, buscando diálogo e aproximação com o governo, a União Internacional Protetora dos Animais alcançou, no ano de 1934, uma grande vitória no que concerne à criação de uma legislação protetora dos animais no Brasil. Antes dessa data existiam normas expedidas por municípios proibindo práticas cruéis, mas a primeira lei de alcance nacional, de 1920, não era específica sobre o tema, versava sobre o funcionamento dos estabelecimentos de diversão, e em meio a outros artigos constava que "Não será concedida licença para corridas de touros, garraios e novilhos, nem briga de gallos e canarios ou quaesquer outras diversões desse genero que causem soffrimentos aos animaes" ${ }^{15} \mathrm{Com}$ a ascensão de Getúlio Vargas ao poder deu-se uma onda legisladora que abrangia os mais diversos assuntos, e nesse quadro geral de mudanças e de desejo de modernizar o país (Schwarcz; Starling, 2015, p.361-362) a associação percebeu uma oportunidade. Em artigo publicado no jornal O Estado de S. Paulo, no dia 4 de maio de 1934, a UIPA dirigiu um memorial diretamente "Ao sr. Getúlio Vargas", recordando ao mandatário que "quase todas as nações do globo possuem leis a respeito", mas que no Brasil as normas "não são extensivas a todos os animais existentes no território nacional”. O texto continha um apanhado histórico da legislação de alguns países e informava que no caso do Brasil projetos de lei sobre o tema foram apresentados ao Congresso Nacional nos anos de 1912, 1914, 1922 e 1929, sem sucesso. O relato é valioso, pois mostra que a luta pela causa animal no país foi um processo contínuo de ação organizada com várias frentes de atuação, incluindo pressão junto aos legisladores, a ponto de a matéria chegar várias vezes ao Legislativo, o que demonstra a ressonância da questão animal em uma parcela da sociedade brasileira.

Em janeiro de 1934 o governo de Getúlio Vargas havia promulgado o Código de Caça e Pesca, regulando, entre vários assuntos, os períodos de defeso da caça e pesca, e proibindo métodos cruéis de captura de bichos. ${ }^{16}$ Contudo, tratava-se de um amparo restrito, voltado para atividade que ao cabo visava aprisionar e matar animais, e que em outros artigos cedia aos interesses dos praticantes da cinegética no país. Os sócios da UIPA intuíram o bom momento para apresentar sua petição, pois Vargas vinha mantendo a tendência de compor com grupos de interesses diversos. Ao atender minimamente as demandas de 
vários segmentos sociais o governo angariava o apoio e a boa vontade de membros destacados e influentes da sociedade brasileira (Miceli, 1979). O artigo escrito pela UIPA no jornal paulista era uma interpelação pública dirigida ao presidente, “a União Internacional Protetora dos Animais, de S. Paulo, pede vênia para submeter à apreciação de v. exa. o projeto de lei incluso, rogando a v. exa. se digne transformá-lo em lei". ${ }^{17} \mathrm{O}$ texto completo do projeto foi transcrito no jornal e assinado por Affonso Vidal, um dos editores da revista Zoophilo Paulista. Para surpresa da entidade seus apelos surtiram efeito, pois no dia 10 de julho de 1934 Getúlio sancionou decreto que estabelecia "medidas de proteção aos animais". ${ }^{18} \mathrm{O}$ fato foi alardeado pela UIPA como uma vitória da própria agremiação, já que a lei aprovada seguia integralmente o texto criado no seio da entidade, tendo esta recebido "comunicação telegráfica diretamente do Palácio do Catete, firmada pelo Sr. Luiz Simões Lopes, informando haver o chefe do governo provisório assinado, ontem, o decreto que orientará, em toda a República, a proteção aos animais, e de cujo anteprojeto é autor o sr. Affonso Vital, um dos esforçados diretores da referida sociedade protetora". ${ }^{19}$

A partir desse decreto todos os animais existentes no país passaram a ser tutelados pelo Estado e os maus tratos a eles dispensados tornaram-se passíveis de gerar multas e até mesmo prisão. A norma elencava uma série de práticas tipificadas como maus tratos, definindo também o que considerava como animal, "Artigo 17. A palavra animal, da presente lei, compreende todo ser irracional, quadrúpede ou bípede, doméstico ou selvagem, exceto os daninhos". Percebe-se que o conceito era limitador, excluindo do amparo, por exemplo, as cobras, bem como os seres tidos como daninhos, isto é, aqueles que prejudicavam a atividade produtiva e econômica humana. Assim, mesmo no âmbito de uma associação que se propunha a defender os animais, vigorava como critério de amparo a utilidade progressiva dos bichos - quanto mais próximos do ser humano e mais importante o seu papel na lida diária (principalmente no campo), maior cuidado mereciam. $\mathrm{O}$ artigo $3^{\circ}$ da lei especificou, em 31 dispositivos, o que "considera maus tratos", dos quais pelo menos vinte tipificações se aplicavam a animais usados como força de trabalho, consumo ou produção, como, "XVI - fazer viajar um animal a pé, mais de 10 quilômetros, sem lhe dar descanso, ou trabalhar mais de 6 horas contínuas sem lhe dar água e alimento; ... XXV - engordar aves mecanicamente".

Na elaboração da lei a UIPA tratou de garantir o protagonismo das entidades protetoras na fiscalização e apuração das infrações, colocando-se como parceira oficial do poder público. $\mathrm{O}$ artigo $2^{\circ}$, no seu $3^{\circ}$ parágrafo, estabelecia 
que "Os animais serão assistidos em juízo pelos representantes do Ministério Público, seus substitutos legais e pelos membros das Sociedades Protetoras de Animais"; e o artigo 16 determinava que "As autoridades federais, estaduais e municipais prestarão aos membros das sociedades protetoras de animais a cooperação necessária para fazer cumprir a presente Lei” (grifos nossos). Não é nosso objetivo fazer uma análise do decreto, o intuito é evidenciar a capacidade operativa e a influência da UIPA ao propor e aprovar projeto de sua autoria, transformando em lei federal uma série de determinações que potencialmente atingiam todos os animais existentes no país, regulando práticas e costumes antigos no trato dos bichos, bem como rotinas de exploração econômica.

O propósito da organização era o de influenciar o maior número de pessoas no que toca à causa animal, mas o direcionamento de suas iniciativas não era aleatório, pois estava claro para a entidade que certos grupos sociais possuíam maior poder simbólico, econômico e político, podendo transformar-se em aliados de peso e propagadores de ideias favoráveis aos bichos. Assim é que no ano de promulgação do decreto foram distribuídos "20.000 mil exemplares da 'lei áurea dos animais', enviando-os, indistintamente, a todas as autoridades estaduais e municipais, a centros religiosos e educativos, a juízes e, notadamente, aos jornais de todo o Brasil, grande parte dos quais transcreveram em suas colunas a lei". ${ }^{20} \mathrm{~A}$ comparação com a lei áurea, que aboliu a escravidão no Brasil, remetia à condição de submissão dos animais do país, pressupondo a vigência de situações de crueldade, exploração, abuso e dominação injusta; mais do que isso, insinuava que circunstâncias de vida tidas como arbitrárias e iníquas para os seres humanos tampouco poderiam prevalecer para os animais. Em que pese o impacto da comparação, a lei não deixou de circunscrever, na própria definição de animal, quais bichos estariam sob o seu amparo, procurando mais regular a forma de usar o trabalho dos animais do que abolir a sua exploração. Certamente, o caráter conciliador da matéria legal em muito contribuiu para a sua aprovação, já que embora alguém dificilmente defendesse o direito de espancar um bicho, as pessoas resistiriam fortemente a limitar ou revogar o uso de animais como transporte, alimento e força de trabalho.

Encontramos algumas referências nos jornais diários sobre casos em que a lei foi aplicada, o que ajuda a traçar um quadro sobre os episódios mais comuns de violência contra os animais: espancar bichos que não obedeciam a comandos, torturá-los por diversão e, não raro, matá-los por vingança, em razão de disputas com desafetos. "Biagio Rivelino foi processado por haver desfechado um tiro de espingarda na cadela de propriedade de Kurt Rigert ... 
a qual morreu", porém o crime teria prescrito por "negligência de funcionário falho". ${ }^{21}$ Em outro caso a justiça foi mais ágil, tendo o Tribunal de Apelação negado recurso contra sentença de primeira instância que condenou pai e filho pela morte de um cão. Segundo relato contido no acórdão “o pobre animal, tomado de pavor, debatia-se nas mãos do seu algoz, que o feria, espaçadamente, com uma faca, até conseguir exterminá-lo", tendo anteriormente os acusados matado outro cachorro "a cacetadas no quintal de sua residência". A pena foi "de 10 dias de prisão e a pagar multa de $200 \$ 000$ por infração do Decreto Federal n. 24.645, de 10 de julho de 1934". O juiz relator do caso afirmou que "só aplausos merece o novo decreto, pois segundo estudos e demonstrações científicas, é sabido que os animais são também dotados de sensibilidade e de instintos aprimorados". ${ }^{22}$

Fica claro, portanto, que a UIPA obteve sucesso considerável em sua proposta de divulgar a causa animal e sensibilizar as autoridades para o problema, e o decreto de 1934 representou um grande triunfo para entidade que, após 39 anos de sua fundação, alcançou reconhecimento público e conquistou considerável terreno de ação. Assim é que nem mesmo a iniciativa privada escapava à vigilância da sociedade protetora, célere em enviar pedidos de explicação a empresas, exigindo mudança de atitude em caso de abuso contra os animais. A fábrica de produtos alimentícios Vigor se viu compelida a esclarecer seus procedimentos em carta: "nas ruas mal calçadas, embora certos carros-tanque nossos pudessem ser puxados por dois animais, o serviço é feito por três". ${ }^{23}$ Cidadãos comuns também eram alvo de denúncias levadas à polícia "ao sr. Nenem Calabrez, por espancar barbaramente um garrote; e ao sr. Alfredo Moreira, por ter entregado no matadouro uma novilha bastante ferida, com as orelhas decepadas". ${ }^{24}$

Já a relação com o governo, em suas diferentes instâncias, nem sempre foi de concordância. Nas páginas de Zoophilo Paulista fica claro o desejo da entidade em interferir e alterar práticas e costumes considerados cruéis e atrasados, e o impresso interpelava constantemente secretários de agricultura, prefeitos, governadores, deputados, vereadores etc. Atenta a tudo que pudesse impactar o bem-estar dos animais, a organização denunciou projeto de lei de vereador da cidade de Campinas, que propunha "a extinção de cães vagabundos por meio de bolas de estricnina". A ideia foi prontamente combatida na primeira página da revista, e sobre a proposta o editorial indagava: "Produto de inconsciência, covardia ou perversidade?”. O fato é que em muitos casos a pressão da entidade, com o apoio da imprensa, obtinha resultado, tendo o "projeto 
monstrengo" sido modificado pela Câmara da cidade. ${ }^{25}$ De modo geral as admoestações dirigidas às autoridades costumavam ser polidas, a organização evitava embates com o poder instituído em razão dos benefícios concedidos pelo governo à UIPA: "Fica o Prefeito autorizado a ceder gratuitamente, o uso e o gozo de um terreno Municipal ... à Sociedade União Internacional Protetora dos Animais, para instalação e funcionamento de um hospital zoophilo". ${ }^{26} \mathrm{~A}$ associação também usufruía de auxílio federal para desempenhar suas atividades, tanto que com a mudança de governo desencadeada pelo movimento de 1930, a organização enviou ofício ao "Dr. Oswaldo Aranha, Ministro da Justiça ... para fazer jus à continuação da subvenção com que temos sido contemplados há vários anos" ${ }^{27}$

Ao longo do tempo a entidade manteve comunicação ativa com as autoridades, buscando capacitar o poder público para lidar com os animas de maneira adequada e digna, apontando a insuficiência da legislação, a falta de fiscalização, o tratamento cruel que os próprios servidores dispensavam aos animais utilizados pelo Estado e a carência de incentivos governamentais dirigidos à associação, que se dizia sobrecarregada por encargos financeiros em nome de um trabalho que, em última instância, beneficiava toda a sociedade.

\section{CONSIDERAÇÕES FINAIS}

Apesar das inúmeras reclamações endereçadas ao poder público, a UIPA buscava manter um tom conciliatório com o governo, apelando nominalmente para as figuras de chefia, declarando sua confiança na "mente esclarecida" dos responsáveis. As palavras mais duras eram reservadas para os servidores de baixa hierarquia, como os carroceiros da prefeitura ou os fiscais que capturavam cães nas ruas, retratados como maldosos e ignorantes pela maneira bruta com que tratavam os animais sob sua guarda. Assim, ao acusar os funcionários menos graduados e elogiar os diretores, chefes, prefeitos e governadores, insinuava-se que as condutas praticadas não seriam do conhecimento do alto escalão, abrindo a possibilidade de que, mediante ato magnânimo, a autoridade responsável interferisse na situação, marcando sua diferenciação, como homens instruídos, dos "rudes" empregados. O diálogo estabelecido e almejado pela revista Zoophilo Paulista era intraelite, os destinatários das mensagens e dos apelos eram as instâncias governamentais, as autoridades (deputados, juízes, delegados etc.), os professores e cientistas, a imprensa e os educandários, 
tidos como capazes de alterar a realidade dos animais no país em razão de sua posição social privilegiada.

Os princípios e o ativismo da UIPA naquele período possuem aspectos semelhantes e diferentes no que toca às sociedades protetoras da atualidade. Semelhantes no perfil aguerrido, voltado para a denúncia, e pela prestação de vários serviços de apoio aos animais abandonados ou maltratados, baseados no voluntariando e na crença nos seus ideais; diferentes em muitos sentidos, principalmente no que toca às relações com o governo, já que os grupos de hoje contam com pouco ou nenhum auxílio financeiro/estrutura concedidos pelas autoridades, mas tal fato confere-lhes maior liberdade para criticar os poderes instituídos. Outro ponto fundamental é a amplitude e a rigidez de princípios da causa animal na contemporaneidade, já que parte significativa das sociedades protetoras são contra o consumo de carne, a utilização de animais em experiências científicas, em esportes e trabalhos (Galvão, 2010, p.18). No caso da UIPA, não encontramos na documentação qualquer referência ao vegetarianismo, e apenas indiretamente a revista tratou da questão da ingestão de carne como assunto sensível, como no poema sobre um boi, "Depois de tanto trabáio / Meu sinhô me quis vendê / Me vendeu pro carnicêro / ... / Vou sofrê a dô da morte! / Botei o joelho em terra / Pra vê meu sangue corrê / Ah, meu Deus, ai que tristeza". ${ }^{28}$ Ela concentrou os seus esforços na proteção dos animais que circulavam pelo ambiente urbano e que possuíam utilidade para o homem, mas tal ênfase também poderia integrar estratégia de convencimento, já que era fácil argumentar em prol da necessidade de a sociedade dedicar cuidados aos animais auxiliares do homem, nem que fosse por interesse econômico. Os animais selvagens mereciam consideração da entidade, mas eram citados no contexto de admoestar os cidadãos a respeitar as leis de caça e pesca e a combater práticas predatórias e cruéis.

A UIPA questionava continuamente o "direto" ilimitado da humanidade em explorar e subjugar os animais. As posições da sociedade fundavam-se em alguns pressupostos, como, por exemplo, o entendimento de que os animais eram seres vivos capazes de sentir dor e prazer, merecendo, portanto, proteção contra o sofrimento desnecessário. Tal princípio, ancorado no pensamento do filósofo Jeremy Bentham (1748-1832), pode parecer óbvio, mas parte da tradição filosófica e científica ocidental amparou-se, durante muito tempo, na proposição de René Descartes de que os animais seriam máquinas, autômatos desprovidos de mente e alma, sendo insensíveis à dor (Descartes, 2001[1637], p.61-66). Essa perspectiva, mesmo que combatida e matizada por muitos, abriu 
caminho para a disseminação, no meio científico, da vivissecção (ato de operar ou dissecar um animal vivo para fins de pesquisa), frequentemente sem uso de anestesia (Carvalho; Waizbort, 2010). Em 1930 a UIPA combatia essa prática com argumentos que ainda remetiam ao debate aberto pelo pensamento cartesiano: "não é lícito retalhar um corpo que dispõe de sensibilidade". ${ }^{29}$

A relação da entidade protetora com a ciência era ambígua. Ao mesmo tempo que celebrava os avanços científicos no que toca à maior compreensão sobre as espécies, deplorava os experimentos em que animais eram manipulados como objetos, principalmente quando os resultados seriam questionáveis, como no caso da vivissecção. O ponto nevrálgico era definir qual tipo/grau de sofrimento animal era necessário. A noção de necessidade, no que toca ao uso dos animais pelos humanos, sofreu profundas transformações a partir do século XVIII, impactando o surgimento de sensibilidades sobre os animais. "O triunfo da nova atitude esteve estreitamente vinculado ao crescimento das cidades e à emergência de uma ordem industrial em que os animais se tornaram cada vez mais marginais ao processo de produção" (Thomas, 1988, p.217). No caso da UIPA, mesmo a indispensabilidade do animal desautorizava os maus-tratos, daí que o decreto de 1934 se preocupou, não em banir o uso dos bichos, e sim estabelecer formas corretas de utilização, elencando a obrigatoriedade de técnicas e instrumentos capazes de minorar o sofrimento.

Para a UIPA a luta em defesa dos animais se dava menos pela afirmação de direitos dos animais frente aos humanos do que pelo dever de restrição do arbítrio do homem sobre os bichos. Em última instância a proteção aos animais se afigurava como uma questão humana, no sentido de que os animais nada exigiriam, cabendo às pessoas se absterem de condutas que as desumanizavam, afastando-as de sua condição especial de seres racionais, autônomos e, portanto, supostamente capazes de autocontrole. Maltratar animais inferiorizava a humanidade, aproximando-a, paradoxalmente, dos bichos bravios, com a ressalva de que esses, ao serem guiados pelos seus instintos e paixões, agiriam de acordo com a própria natureza. Em relato publicado em Zoophilo Paulista, intitulado "Desumanidade", a revista denuncia a ação de homens que atearam fogo em um cão, matando-o, descrevendo a situação nos seguintes termos: "Imagine o leitor o que sofreu a pobre vítima da falta de sentimento daquelas feras", tendo a sociedade o dever de "castigar os tão desumanos seres" ${ }^{30} \mathrm{Na}$ prática do ato cruel os perpetradores teriam abdicado da própria humanidade, tornaram-se feras, a pior versão de um animal, sanguinário e brutalizado. Negar humanidade aos praticantes de tamanha crueldade afastava 
o perigo do reconhecimento de si mesmo no partilhar de uma condição humana comum, capaz de tamanha violência.

Nos discursos produzidos pela UIPA os animais seriam entes que, mesmo demonstrando certo grau de inteligência e linguagem, possuiriam esses atributos em um nível tosco, incomparável com os humanos. Além dessas diferenças, a associação, de tendência claramente cristã, reconhecia que os bichos, apesar de criaturas de Deus, careceriam da centelha divina atribuída aos homens. Com base em tais diferenciações as pessoas estariam autorizadas a fazer uso dos animais para suprir necessidades, porém, na medida em que ocorressem avanços técnicos, científicos e sociais seria desejável diminuir essa exploração. O fato é que as contradições dos discursos e das atitudes da organização protetora com relação ao status dos animais devem ser vistas como parte de um dilema cultural amplo, onde, no que se refere aos bichos, "existe o entendimento das origens comuns, de capacidades compartilhadas, mas também, e simultaneamente, a crença no direito do ser humano de dominação" (Fudge, 2002, p.21, trad. NO).

Considerando as falas e a atuação da UIPA, bem como o projeto por ela proposto na composição do decreto de 1934, qual tipo de animal merecia, prioritariamente, a defesa da entidade? Claramente aqueles animais mais próximos da cultura do que da natureza. Ao fazermos tal afirmação não estamos encampando a separação entre natureza e cultura, e sim considerando que, para o caso analisado, os bichos mais próximos dos investimentos humanos (afetivo, de trabalho, consumo), tinham primazia na proteção. Assim, conceder-lhes direitos ou cuidados era reconhecê-los como agregados da humanidade, com uma longa história compartilhada; cães, gatos, cavalos, bois e galinhas seriam animais "menos naturais", sujeitos a um grau considerável de ordem e controle. Faz sentido, portanto, que a crueldade praticada por pessoas contra esses bichos fosse qualificada como desumana: já que tais animais seriam, por associação e proximidade, algo relativo ao humano, maltratá-los era um ataque à organização social da qual faziam parte.

Os discursos analisados não pugnavam pela igualdade entre homens e animais, e esses eram constantemente referidos como "nossos irmãos inferiores", “criaturas mudas" e os "irracionais”. A relação era de tutela, devendo o ser humano, ápice da escala evolutiva e delegado de Deus na terra, zelar pelo trato digno daqueles que não podiam cuidar de si ou escapar das ações maldosas. Frisava-se constantemente que o poder vinha acompanhado da responsabilidade, devendo a sociedade, que tanto proveito tirava dos bichos, 
ampará-los e, se possível, tratá-los com carinho. No caso dos chamados animais daninhos ou perigosos não se justificava o mau trato, mas se reconhecia a necessidade de combatê-los ou controlá-los em nome da economia, da higiene e da saúde. O espírito da causa protetora era reformador, visando alterar condutas, hábitos e costumes, melhorar a vida dos bichos e, no caso de ter que sacrificá-los, fazê-lo de modo digno e indolor. Os direitos dos animais eram defendidos quase sempre como medidas que seriam benéficas aos humanos; trazendo vantagens morais, intelectuais, econômicas, sanitárias e de melhor organização do espaço urbano, esses direitos raramente eram evocados com base em um valor intrínseco dos bichos.

O que a trajetória da UIPA demonstra é que a luta pela defesa dos animais no Brasil é mais longa do que imagina o senso comum, e que a causa apresentava contornos fortes e estruturados já nas primeiras décadas do século XX, de tal forma que as associações protetoras foram consideradas interlocutoras e auxiliares legítimas do poder público, a ponto de receberem atribuições oficiais e de influenciarem a promulgação de leis no país. Sua atuação preferencial nos centros urbanos se explica pela imensidão territorial do Brasil, pelos recursos limitados da entidade, tanto econômicos como de pessoal, e pelo fortalecimento de uma nova sensibilidade por parte dos citadinos, alijados em parte das práticas rurais, e cada vez menos tolerantes com cenas de morte, do sangue, do abate ao alcance dos sentidos, dos dejetos orgânicos, das infestações trazidas pelos bichos, da visão de seres feridos ou mutilados (Hodak, 1999, p.163). No processo de defender os animais e de conscientizar a população sobre a sua importância - mesmo que os argumentos utilizados fossem em grande parte antropocêntricos -, a União Internacional Protetora dos Animais questionou a pretensão humana de ser a única espécie com direito à vida e ao gozo de uma existência digna e pacífica.

\section{REFERÊNCIAS}

AGULHON, Maurice. Le sang des bêtes. Le problème de la protection des animaux en France au XIXème siècle. Romantisme, Paris, n.31, p.81-110, 1981.

AMARO, Alexandra; FELGUEIRAS, Margarida Louro; LENCASTRE, Marina Prieto. A educação e o movimento de defesa dos animais não humanos em Portugal na transição do século XIX para o século XX. Revista Tempos e Espaços em Educação, Lisboa, v.6, n.10, p.9-25, jan./jun. 2013. 
APROBATO FILHO, Nelson. O couro e o aço: sob a mira do moderno: a "aventura" dos animais pelos "jardins" da Paulicéia, final do século XIX / início do XX. Tese (Doutorado em História) - Departamento de História, Universidade de São Paulo. São Paulo, 2007.

ARIAS NETO, José Miguel. Primeira República: economia cafeeira, urbanização e industrialização. In: FERREIRA, Jorge; DELGADO, Lucilia de Almeida Neves (Org.) O tempo do liberalismo excludente: da Proclamação da República à Revolução de 1930. Rio de Janeiro: Civilização Brasileira, 2006. p.191-229.

BARATAY, Eric; MAYAUD, Jean-Luc. Un champ pour l'histoire: l'animal. Cahiers d'histoire, Lyon, n.42, p.410-470, 1997.

CARVALHO, André Luis de Lima; WAIZBORT, Ricardo. A dor além dos confins do homem: aproximações preliminares ao debate entre Frances Power Cobbe e os darwinistas a respeito da vivissecção na Inglaterra vitoriana (1863-1904). História, Ciências, Saúde - Manguinhos, v.17, n.3, p.577-605, jul./set. 2010.

CLUTTON-BROCK, Juliet. Animals as domesticates: A World View through History. East Lansing: Michigan State University Press, 2012.

DESCARTES, René. Discurso do Método [1637]. São Paulo: Martins Fontes, 2001.

DUARTE, Regina Horta. À sombra dos fícus: cidade e natureza em Belo Horizonte. Ambiente \& Sociedade, São Paulo, v.10, n.2, p.25-44, 2007.

Cavalinhos, leões e outros bichos: o circo e os animais. Varia História, Belo Horizonte, v.26, n.26, p.97-106, 2002.

Pássaros e cientistas no Brasil: Em busca de proteção, 1894-1938. Latin American Research Review, Austin, EUA, v.41, n.1, p.3-26, 2006.

DUARTE, Regina Horta; OSTOS, Natascha S. Carvalho de. Entre Ipês e Eucaliptos. Nómadas, Bogotá, n.22, p.74-85, abr. 2005.

FAVRE, David; TSANG, Vivien. The Development of Anti-Cruelty Laws During the 1800s. Detroit College of Law Review, Detroit, v.1, p.1-35, 1993.

FUDGE, Erica. Animal. London: Reaktion Books, 2002.

Foreword. In: FEW, Martha; TORTORICI, Zeb (Ed.) Centering Animals in Latin American History. Durham: Duke University Press, 2013. p.IX-XI.

GALVÃO, Pedro (Org. e Trad.) Os animais têm direitos? Perspectivas e argumentos. Lisboa: Dinalivro, 2010.

HODAK, Caroline. Les animaux dans la cité: pour une histoire urbaine de la nature. Genèses, Paris, n.37, p.156-169, 1999.

HRIBAL, Jason C. Animals, agency, and class: writing the history of animals from below. Human Ecology Review, Canberra, v.14, n.1, p.101-112, 2007.

MICELI, Sérgio. Intelectuais e classe dirigente no Brasil (1920-1945). Rio de Janeiro: Difel, 1979.

MÓL, Samylla; VENANCIO, Renato. A proteção jurídica aos animais no Brasil: uma breve história. Rio de Janeiro: Ed. FGV, 2014. 
MONZOTE, Reinaldo Funes. Animal labor and protection in Cuba. Changes in relationship with animals in the nineteenth century. In: FEW, Martha; TORTORICI, Zeb (Ed.) Centering Animals in Latin American History. Durham: Duke University Press, 2013. p.209-242.

PINHEIRO, Valter Cesar. Folheando a obra (e a vida) do grão-senhor da Villa Fortunata: um estudo sobre René Thiollier, $2 \mathrm{v}$. Tese (Doutorado em Estudos Literários) - FFLCH, Universidade de São Paulo (USP). São Paulo, 2014. Disponível em: http://www.teses.usp.br/teses/disponiveis/8/8146/tde-04022015-114953/pt-br.php; Acesso em: 12 dez. 2016.

SANJAD, Nelson et al. Documentos para a história do mais antigo jardim zoológico do Brasil: o parque zoobotânico do Museu Goeldi. Boletim do Museu Paraense Emílio Goeldi, Belém, v.7, n.1, p.197-258, jan./abr. 2012.

SCHWARCZ, Lilia Moritz; STARLING, Heloisa Murgel. Brasil: uma biografia. São Paulo: Companhia das Letras, 2015.

SEDREZ, Lise Fernanda. Cidade alagada: chuvas de verão, classe e estado no Rio de Janeiro 1966-1967. Maquinações, Londrina, v.1, p.14-15, 2007.

TEIXEIRA, Luiz Antonio; SANDOVAL, Maria Regina Cardoso; TAKAOKA, Neide Yumie. Instituto Pasteur de São Paulo: cem anos de combate à raiva. História, Ciências, Saúide - Manguinhos, Rio de Janeiro, v.11, n.3, 2004. Disponível em: http://www.scielo.br/scielo.php?script=sci_arttext\&pid=S0104-59702004000300011; Acesso em: 3 set. 2016.

THOMAS, Keith. O homem e o mundo natural: mudanças de atitude em relação às plantas e aos animais, 1500-1800. São Paulo: Companhia das Letras, 1988.

TORTORICI, Zeb; FEW, Martha. Introduction. Writing Animal Histories. In: FEW, Martha; TORTORICI, Zeb (Ed.) Centering Animals in Latin American History. Durham: Duke University Press, 2013. p.1-27.

VIEIRA, David Durval Jesus. A cidade e os "bichos": poder público, sociedade e animais em Belém (1892-1917). Dissertação (Mestrado em História) - Universidade Federal do Pará (UFPA). Belém, 2015.

WANG, Jessica. Dogs and the Making of the American State: Voluntary Association, State Power, and the Politics of Animal Control in New York City, 1850-1920. The Journal of American History, p.998-1024, march 2012.

\section{NOTAS}

${ }^{1}$ Professora substituta do Departamento de História da UFMG, pós-doutoranda do Programa de Pós-Graduação em História da UFMG. Pesquisa financiada pelo Conselho Nacional de Desenvolvimento Científico e Tecnológico - CNPq (processo: 165936/2015-0).

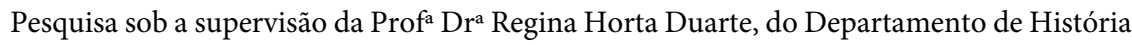


da UFMG. Todos os exemplares da revista Zoophilo Paulista citados neste artigo pertencem ao acervo particular da Prof ${ }^{a}$ Regina Horta Duarte, a quem agradecemos por ceder, tão generosamente, a documentação para consulta. Este artigo constitui uma etapa de pesquisa desenvolvida pelo grupo História e Natureza, liderado pela referida professora, que em próxima fase expandirá a investigação com base em acervo documental inédito.

2 O clipe oficial da música está disponível em: https://www.youtube.com/ watch?v=QcZNV0HVo9Y; Acesso em: 18 mar. 2017. O filme é categorizado como "vídeo documentário", nele o cantor aparece visitando uma instituição protetora de animais. À medida que a música se desenvolve surgem imagens de cães interagindo com o artista, que promove campanha pela adoção e o cuidado com os bichos. Até o momento, e apenas nessa plataforma, o clipe teve mais de 31 milhões de visualizações.

${ }^{3}$ A pesquisa do IBGE está disponível em: http://saladeimprensa.ibge.gov.br/pt/noticias?view= noticia\&id= 1 \&idnoticia $=2902 \&$ busca $=1 \& \mathrm{t}=$ pns-2013-tres-cada-quatro-brasileiroscostumam-buscar-atendimento-medico-rede-publica; Acesso em: 4 jul. 2015. Para a repercussão na imprensa ver: http://f5.folha.uol.com.br/bichos/2015/06/1636937-brasileiros-temmais-cachorros-que-criancas-segundo-pesquisa-do-ibge.shtml; Acesso em: 4 jul. 2015.

${ }^{4}$ Disponível em: http://abinpet.org.br/site/setor-pet-chega-a-r-18-bilhoes-em-2015-mas-nao-sem-os-efeitos-da-crise/; Acesso em: 20 fev. 2017. O setor é dividido nas áreas de alimentação, serviços, itens de cuidados e medicamentos.

${ }^{5}$ Uma listagem bibliográfica em inglês sobre os estudos dos animais está disponível em: http://www.animalstudies.msu.edu/bibliography.php. No caso da França consultar BARATAY; MAYAUD, 1997.

${ }^{6}$ Vem crescendo o número de trabalhos dedicados a estudar o que em inglês se denomina de animal agency, isto é, os animais como seres capazes de "influenciar e guiar as suas próprias vidas". Obviamente, o tema não deixa de ser mediado pelo olhar humano, mas traz informações relevantes sobre as ações dos bichos frente à dominação humana, como: desobedecer a comandos, vocalizar descontentamento, danificar objetos, fugir, recusa em se locomover e em realizar tarefas, agressões físicas, "roubo" de alimentos etc. (HRIBAL, 2007, p.102-103).

${ }^{7}$ As primeiras iniciativas visando a proteção aos animais (objetivando o bem-estar animal e não interesses diretos dos homens), surgiram na Inglaterra do século XIX. Leis esparsas tentavam prevenir a crueldade contra o gado (1822) e proibir lutas entre cães (AMARO; FELGUEIRAS; LENCASTRE, 2013, p.13). No ano de 1824 foi fundada em Londres a Royal Society for the Prevention of Cruelty to Animals, inspirando daí em diante a composição de grupos semelhantes pelo mundo (MÓL; VENANCIO, 2014, p.19).

${ }^{8}$ A. C. Editoriais. Carta Paulista. A Sociedade Protectora dos Animaes. A República, Curitiba, ano LXV, n.73, 5 abr. 1930, p.3.

${ }^{9}$ Casa Orestes (anúncio). Zoophilo Paulista, São Paulo, ano XII, n.126, dez. 1930, s.n.p.

${ }^{10} \mathrm{~A}$ caracterização de animais como domésticos ou selvagens não diz respeito à espécie, $\mathrm{e}$ sim à sua situação de vida. Domésticos (incluindo os chamados animais de companhia) 
são aqueles mantidos em "cativeiro por uma comunidade humana que possui total controle sobre sua criação, organização territorial e suprimento alimentar". Os animais selvagens não dependem de fontes de comida produzida por humanos e ocupam territórios próprios. De acordo com tal caracterização uma onça é quase sempre um bicho selvagem, mas se em cativeiro, em um zoológico por exemplo, passaria a ser doméstico. CLUTTON-BROCK, 2012, p.3 apud Animal Studiest at Michigan State University, disponível em: http://animalstudies.msu.edu/; Acesso em: 7 mar. 2017.

${ }^{11}$ Horrível Desastre. Zoophilo Paulista, São Paulo, ano XII, n.121, jun. 1930, s.n.p.

${ }^{12}$ Constitui-se nesta capital uma nova sociedade destinada à proteção dos animais. Diário Nacional, São Paulo, n.1483, 9 jun. 1932, p.5.

${ }^{13}$ Palavras de um oposicionista da Protetora dos Animais. A Gazeta, São Paulo, n. 7.829, 10 mar. 1932, p.4.

${ }^{14}$ Não maltrate os animais... Protetora hipotética - O que não se faz e o que se deveria fazer. A Gazeta, São Paulo, n.8.213, 29 maio 1933, p.8.

${ }^{15}$ BRASIL. Decreto n.14.529, 9 dez. 1920. Dá novo regulamento ás casas de diversões e espetáculos públicos. Disponível em: http://www2.camara.leg.br/legin/fed/decret/1920-1929/decreto-14529-9-dezembro-1920-503076-republicacao-93791-pe.html; Acesso em: 5 abr. 2016.

${ }^{16}$ Decreto-lei n.23.672, 2 jan. 1934. Disponível em: http://www2.camara.leg.br/legin/fed/ decret/1930-1939/decreto-23672-2-janeiro-1934-498613-publicacaooriginal-1-pe.html; Acesso em: 14 mar. 2016.

${ }^{17}$ Proteção aos Animais. Um memorial da União Internacional Protetora dos Animais ao chefe do governo provisório. O Estado de S. Paulo, São Paulo, ano LX, n.19.794, 4 maio 1934, p.5.

${ }^{18}$ Decreto n.24.645, 10 jul. 1934. Disponível em: http://www.planalto.gov.br/ccivil_03/decreto/1930-1949/D24645.htm; Acesso em: 13 maio 2015.

${ }^{19}$ União Internacional Protetora dos Animais. Correio Paulistano, São Paulo, ano LXXXI, n.24.017, 13 jul. 1934, p.7.

${ }^{20}$ A proteção aos animais no Brasil. Correio Paulistano, São Paulo, ano LXXXIV, n.25.206, 13 maio 1938, p.12.

${ }^{21}$ Forum criminal. Correio Paulistano, São Paulo, ano LXXXV, n.25.493, 18 abr. 1939, p.17.

${ }^{22}$ Diário Oficial de São Paulo, São Paulo, “Botucatú”, 15 jan. 1942, p.32.

${ }^{23}$ A proteção dos animais nesta capital. Zoophilo Paulista, São Paulo, ano XII, n.121, jun. 1930, s.n.p.

${ }^{24}$ A proteção dos animais em Bauru. Zoophilo Paulista, São Paulo, ano XII, n.123, ago. 1930, s./p.

${ }^{25}$ Um gesto desastrado. Zoophilo Paulista, São Paulo, ano XII, n.125, out. 1930, s.n.p. 
${ }^{26}$ Resolução n.128. Prefeitura Municipal de São Paulo, 2 out. 1928. Zoophilo Paulista, São Paulo, ano XII, n.121, jun. 1930, s.n.p.

${ }^{27}$ Em prol da União Internacional Protetora dos Animais. Zoophilo Paulista, São Paulo, ano XII, n.127, fev. 1931, s.n.p.

${ }^{28}$ Trovas caipiras. A vida e as tristezas e injustiças que sofreu um boi desde que nasceu. Zoophilo Paulista, São Paulo, ano XIII, n.130, maio 1931, s.n.p.

${ }^{29}$ G. CIALURRI. A Lucta Anti-Viviseccionista. Zoophilo Paulista, São Paulo, ano XII, n.122, jul. 1930, s.n.p.; grifo nosso.

${ }^{30}$ Desumanidade. Zoophilo Paulista, São Paulo, ano XII, n.123, ago. 1930, s.n.p.; grifos nossos.

Artigo recebido em 3 de abril de 2017. Aprovado em 6 de junho de 2017. 